\title{
TEN-YEAR SODIUM-REACTOR \\ DEVELOPMENT PROGRAM
}

Facsimile Price $\$ \frac{2.60}{1 \times 04}$

Available from the

Office of Technical Services

Department of Commerce

Washington 25, D. C.

\section{ATOMICS INTERNATIONAL}

A DIVISION OF NORTH AMERICAN AVIATION, INC. P.O. BOX 309 CANOGA PARK, CALIFORNIA

CONTRACT: AT(11-1)-GEN-8

ISSUED: APRIL 11, 1959 


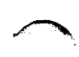




\section{CONTENTS}

Page

Abstract. - ... . . . . . . . . . . . . . . . . 4 4

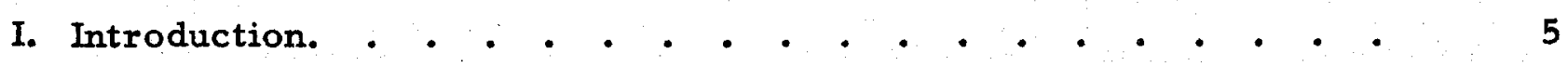

A. Status of Sodium Reactor Technology - . . . . . . . .

B. Sodium Cooled Reactor Fuel . . - . - • . . . . . . 7

C. Reactor System Fabrication - . - . . • . . . . . . 9

D. Reactor Physics . . . . . . . . . . . . . . 10

E. Power Generation . . . . . . . . . . . . . . 10

F. Reactor Safety and Containment. - . . . . . . . . . 11

G. Liquid Metal Handling . • . . • . . . . . . . . . 12

H. Current and Predicted Capital Costs . . . . . . . . . 13

II. Sodium Reactor Program for Economic Power . . . . . . . 16

III. Appendix - Sodium Cooled Reactor Fuel Development . . . . . 23

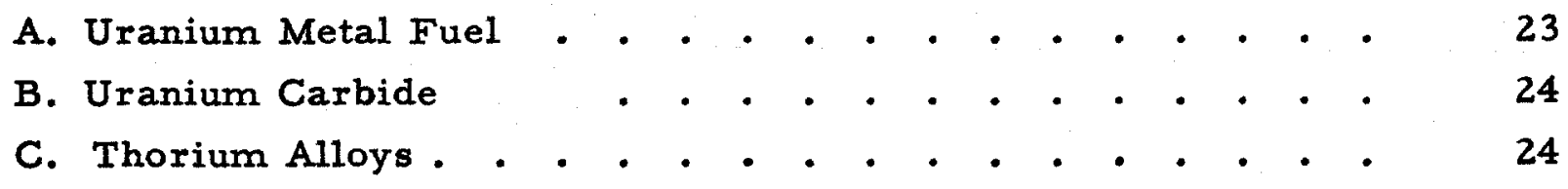




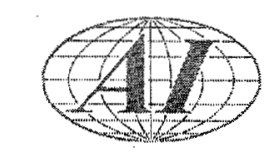

\begin{abstract}
A 10-year program of development and construction of large-scale, sodiumcooled reactors is summarized in this report. The current state of development of the SGR and its associated components is sufficiently advanced to permit construction of economic plants within the 10-year period. Two advanced Sodium Reactor concepts are presented. A construction program involving two reactor experiments and two full-scale plants with a capacity of $550 \mathrm{Mwe}$, together with associated development, is estimated to cost $\$ 216$ million. Of this amount approximately $\$ 106$ million would be borne by the AEC and the remainder by power utility companies. Escalation and construction loan interest charges are included in these figures. The cost of power from the larger power plant would be approximately $6 \mathrm{mills} / \mathrm{kw}-\mathrm{hr}$, based on 1959 dollars.
\end{abstract}




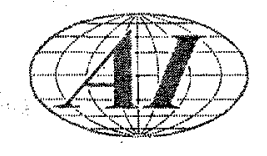

\section{INTRODUCTION}

The technology of sodium cooled reactors is now sufficiently advanced, after 10 years of effort in several programs, to predict with confidence the potentialities of sodium-coolant-reactor types to produce economical nuclear power. At least two avenues are now being explored: sodium graphite thermal reactors and sodium-cooled breeder systems of several configurations. Depending on the needs of the future, both immediate and long range, either of these systems appears able to produce competitive power at approximately 6.0 mills; the SGR system has advanced to the point where predictions based on experimental evidence and on fixed price component and system bids permit rather accurate extrapolations of future costs. Economical power within 10 years from this type of reactor is more than a probability; it appears to be a certainty if prosecuted vigorously according to the plan set forth in this document.

Breeder technology, which depends on sodium cooling, is limited so far by lack of exact physics information; confident predictions as to the ultimate future of fast and epithermal systems must await experiments being performed at several places within the country to uncover fundamental constants of nature.

The technical advances necessary to bring about economic power are at hand; the technical exploitation of cost reduction by increased performance of components now waits only on actual demonstration in a series of reactors to bring about the desired competitive costs from the sodium graphite system.

This competitive power cost can be made available by using proven steam cycles, by using conventional equipment demonstrated satisfactorily many times in fossil-fired plants, and by using the technology developed piecemeal in the several sodium-cooled-reactor programs entered into over the past 10 years.

\section{A. STATUS OF SODIUM REACTOR TECHNOLOGY}

Sodium coolant was extensively developed by the Navy under the SEA WOLF program. Although the reactor itself was epithermal in spectrum, the coolantsystem components and the technology of liquid metal associated therewith were not unique to any particular reactor. Extensive and valuable contributions to the 


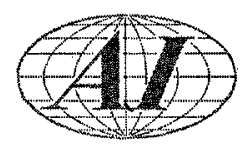

technology of handling liquid metals were made by this program; previous industrial experience had been limited to routine process equipment widely used in the chemical industry at temperatures of 400 to $500^{\circ} \mathrm{F}$. The SEA WOLF program pioneered in advancing the handling of these liquid metals to temperatures in the 800 to $900^{\circ} \mathrm{F}$ range, although it should be noted that the peculiar necessities of submarine construction placed unique requirements on all system components. Developers of this system were faced on the one hand with the necessity for increasing the temperature range for production of useful superheated steam, and on the other hand with severe requirements for mechanical shock resistance, space limitations, and the accessibility required for a warship power plant. These requirements were met with varying degrees of success; with the exception of the steam generating equipment, the SEA WOLF, during a 2-year operating period, is reported to have suffered no casualty to reactor-compartment operating machinery. The reactor plant is currently being disassembled, indicating further that accessibility after reasonably prolonged operation is not severely restricted.

EBR I, cooled by a sodium-potassium eutectic alloy, actually operated prior to the SEA WOLF. Coolant system components of this plant were designed for maximum reliability at temperatures comparable to the SEA WOLF, and were not subjected to the same limitations with regard to space and mechanical shock-proofness. The operating history of the heat transfer system of the EBR I has been one of notable and continuous success; though small in heat capacity, this system has demonstrated that liquid-metal reactor coolants can be operated reliably over a long period of time. EBR I began operation in 1952 and is still operating today with the original heat-transfer-system equipment.

Encouraged by the success of EBR I, and by the progress being made in SEA WOLF development, the SRE (Sodium Reactor Experiment) was initiated in 1955. The reactor itself is a fully thermal, graphite-moderated design, as differentiated from the fast EBR I and epithermal SEA WOLF. Coolant temperatures and gradients were increased from SEA WOLF and EBR I conditions in this design, and development work was started to show that these increased conditions would not pose significantly harder problems than those already experienced. SRE design was predicated on maximum use of commercially available heat-transfer-system components, as funds and schedule would not 


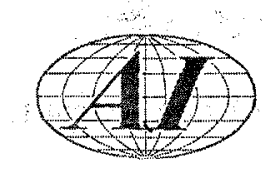

permit the extensive development work noted above for the SEA WOLF. That this approach was successful to a large degree is evidenced by the regular operation of the SRE at this time. Heat-transfer-system components, while not achieving the degree of trouble-free operation experienced by the SEA WOLF, have generally proved reliable even though designed and constructed to quasicommercial standards.

Thus, there are guide posts available which indicate rather clearly what can be achieved with both maximum and minimum developmental efforts and restrictions on liquid-metal-system design. The optimum, as might be expected, is between these points, and quite probably toward the "minimum" end of the scale. With increasing bodies of experience, achieved through relatively modest expenditures of funds, when compared to those expended on other coolants, additional sophistication in liquid-metal, high-temperature, heat-transfer systems has been acquired. Initial attempts at liquid-metal systems followed design patterns similar to those of conventional process systems. However, it has been realized that liquid metal possesses very unique characteristics; the advanced technology being developed today at the several laboratories involved in this work is producing systems and components which reflect these unique capabilities and limitations. The Enrico Fermi and EBR II reactors are cases in point; these system designs mark milestones in the process of divorcing liquid-metal systems from traditional system design as employed over the years by other industries. The superb heat-transfer properties of liquid metals, which lead to high power density, are being exploited; these same properties lead to very rapid temperature transients under some conditions, and these unique transients are being dealt with by designs which must necessarily depart from the familiar.

Advanced designs, taking advantage of all this previously acquired experience, have now been generated; the technology of high-temperature liquid metals for the production of high-pressure, highly superheated steam is available now.

\section{B. SODIUM COOLED REACTOR FUEL}

The production of highly superheated steam necessitates heating of liquid metal to temperatures of the order of $1200^{\circ} \mathrm{F}$. Metallic uranium fuels 


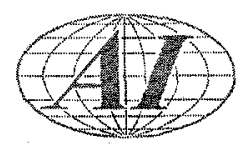

operating at these temperatures are generally unsatisfactory unless alloyed with strengthening agents. Uranium dioxide, upon which a very great effort has been expended in other programs, is as satisfactory for power generation in sodiumcooled reactors as it is in water-cooled reactors where its use is an absolute necessity. The poor heat-transfer characteristics of uranium dioxide, however, are incompatible with the excellent heat-removal properties of the liquid metal. Heat fluxes on the order of $300,000 \mathrm{Btu} / \mathrm{ft}^{2} / \mathrm{hr}$, which correspond to the heatremoval capacity of pressurized or boiling water, appear feasible; heat fluxes on the order of 1 to $1-1 / 2$ million $\mathrm{Btu} / \mathrm{ft}^{2} / \mathrm{hr}$, which are readily obtainable with liquid-metal coolants, do not appear practical with oxide fuels due to the extremely high central temperatures which must be generated in order to retain fuel elements of reasonable fabricability and cost. Therefore, it is essential that fuels of rather high thermal conductivity be employed in liquid-metal-cooled reactors, in order to achieve the power density made possible by liquid-metal coolants. Uranium alloys containing from 1-1/2 to $10 \%$ molybdenum are currently being irradiated at numerous sites in the United States; results are sufficiently encouraging to have made uranium-molybdenum alloys the reference fuel for both the Fermi reactor and the first loading of the Hallam reactor. Thorium - uranium alloys, both cast and wrought, have been irradiated to exposures of $10,000 \mathrm{Mwd} / \mathrm{t}$ with acceptable fission-gas retention at temperatures suitable for the production of $1200^{\circ} \mathrm{F}$ liquid metal, thus demonstrating that this is still another approach to high-temperature fuel technology. Uranium monocarbide has been irradiated under the same high-temperature conditions to 6500 $\mathrm{Mwd} / \mathrm{t}$ with even more encouraging resistance to swelling. Uranium-carbide development is still in its infancy, both as to production methods and to statistically significant irradiation stability demonstration. It should be noted in this connection, however, that there appears to be no inherent reason why this fuel should not be as stable as oxide, and eventually competitive in cost. The funds expended in development to date, which have produced these encouraging results, have been only a fraction of a percent of that expended on oxide development. Carbide holds a bright hope for the future, as its density is at least $50 \%$ greater than that of oxide (leading to smaller cores) and 14 times greater than oxide in thermal conductivity (leading to higher power densities at reasonable central fuel temperatures). 


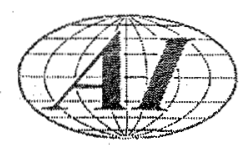

From the foregoing, it can be seen that some high-temperature fuels are available now, subject only to the same question that affects all other fuels: the question of fuel-cycle cost. Even more promising fuels are under development and will be available in the immediate future after expenditure of only a fraction of the development cost already expended on oxide.

In addition, it must be noted that liquid-metal-cooled reactors have far more flexibility in current and potential fuel choices, because of the inert nature of sodium and NaK in contact with alloys and compounds of conceivable fissionable and fertile materials. No evidence of fuel - coolant reaction has been observed with either the oxide, metals, carbide, or alloys. This is fortunate, as a much wider choice of materials is thus available to the liquid-metal-reactor designer as fuel technology progresses.

\section{REACTOR SYSTEM FABRICATION}

Liquid metals have the outstanding advantage of a long liquid range with extremely modest vapor pressures. This in turn indicates that there is no apparent limit on the fabrication of vessels and components. Highly pressurized systems, e: g., the water-cooled reactors, reach a size beyond which fabrication difficulties mount very rapidly. The task confronting the fabricator of pressure vessels with walls over 8 inches thick, and diameters of $15 \mathrm{feet}$, is enormous; quality control in these cases is difficult, and the facilities for forming such massive components place a very real upper limit on the size obtainable. By contrast, the low pressures involved in liquid-metal systems demand only nominal vessel thickness, more comparable to the containment shells required around the high-pressure systems than to the pressure vessels of the systems themselves. These containment vessels, which so far have been required in every high-pressure-reactor application, have, of course, been erected in the field. Field erection of large, relatively thin-walled, sodium-system components is equally feasible.

As far as fully thermal sodium-cooled reactors are concerned, physical size of the reactor is affected more by the neutron physics of the moderator than by power density requirements. Consequently, the physical size of this type of reactor increases only very slowly with increases in power, as contrasted 


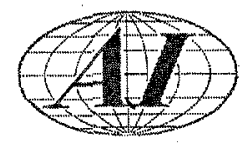

with other reactor systems. Thus, most of the engineering difficulties experienced in constructing experimental and prototype reactors of modest power are resolved for reactors of greater power by the successful operation of the prototype. Heat-exchange-equipment size is, of course, rather directly proportional to power level, which problem may be met either by larger heatexchange units or multiplying the number of small units, all of which are external to the reactor itself. From these considerations, it can be seen that the scaleup problems from small experimental and prototype reactors are nowhere as grave as those encountered by systems in which size is a direct function of power level.

\section{REACTOR PHYSICS}

The stability of thermal sodium-cooled reactors has been amply demonstrated by extensive pile oscillator tests on the SRE. This type of reactor is not fraught with uncertainties in void coefficients and flux peaking such as beset boiling and pressurized water systems. The low-pressure liquid-metal systems afford practical use of thimbles, etc., to avoid unpleasant control-rod-withdrawal effects which necessitate such schemes as nonabsorbing "tails" on control rods, adding further complication to the mechanical design of both core and vessel.

Long-term reactivity of the fuels suitable for liquid-metal systems poses the same problems as for all fixed-fuel, long-fuel-life reactors regardless of configuration and moderator. Only the completion of long-burnup experiments, presently underway, will yield answers to this problem inherent in all reactors. The small amount of flux peaking in the sodium reactor is also advantageous when fuel life is limited by maximum exposure.

\section{E. POWER GENERATION}

Highly superheated steam at high pressures can be made from low-pressure sodium, because of the high temperatures to which sodium can be raised. Net plant thermal efficiencies on the order of $40 \%$ can be achieved without complex dual-function reactor cores (combination boiling-water-cooled and steam-cooled). Development of fuel elements required to perform this "nuclear" superheating function is scarcely started; production of superheated steam from sodium-heated steam generators is accomplished routinely both at EBR I and the SRE. 


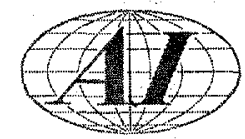

Chemical compatibility of sodium and water is such that quite elaborate precautions to prevent intermixture have been taken in past sodium - steam generator designs. This heritage stems basically from the SEA WOLF, in which a sodium - water reaction would have resulted in the release of highly radioactive reaction products inside a submarine hull. Subsequent steamgenerator designs, made with this philosophy implied if not explicit, have been extremely expensive. Fortunately, the Atomic Power Development Associates group has conducted a series of experiments indicating that the consequences of this reaction, when radioactivity is not involved, are not so severe as to be disabling. In central-station-type plants, a secondary liquid-metal loop of some configuration will normally be employed, and therefore a problem of radioactivity does not arise. The way has thus been opened toward production of "single wall" steam generators of simple design and consequently greatly reduced fabrication cost.

Additional simplifications in heat-exchange equipment, particularly liquid metal to liquid metal, are becoming apparent as a design philosophy based on liquid metals per se, as distinguished from conversion of more familiar and conventional process systems, is developed. Integration of primary and secondary heat-exchange systems, as well as steam-generating systems, in system concepts is described briefly in the program of reactor progress proposed at the end of this paper.

In summary, high-thermal-efficiency plants cooled with sodium and operating at steam conditions demonstrated to be satisfactory by fossil-fuel plants, are in existence now; developments in the immediate future will lead to reactor power plants producing steam comparable to that of the most modern fossil-fuel plants available today and in the foreseeable future.

\section{F. REACTOR SAFETY AND CONT AINMENT}

The stability of sodium-cooled, graphite-moderated reactors has been demonstrated beyond doubt by the SRE. Sodium reactors utilizing epithermal and fast neutron spectra are still in a nascent stage, and until their stability is as well demonstrated as in the SGR, some form of containment will undoubtedly be required. Such containment as is required will stem from the response of the 


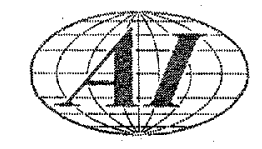

reactor core to sudden reactivity changes rather than from requirements on the liquid-metal-cooling system. Elaborate structures are not required for thermal sodium-cooled reactors, as has been shown in the SRE and Hallam Nuclear Power Facility (HNPF) designs.

With the system simplifications made possible by experience in handling liquid metals; such as the elimination of piped primary systems, even greater savings in construction cost are certain. The potential damage from a straight boiler explosion is not greater than for fossil-fired systems; the additional complications of sodium-water reactions in case of failure have been demonstrated by APDA to be simply and inexpensively controlled.

\section{G. LIQUID METAL HANDLING}

Despite the many obvious advantages of liquid metal as a coolant when compared to other media, it must be stated that there are some disadvantages. Only when these disadvantages are dealt with in a rational fashion can sodium systems be seen in their truly advantageous light. The chemical reactivity of alkali metals with oxygen requires that an inert atmosphere be maintained wherever these metals may come in contact with a gas. Helium has been used in the past as this inert "cover gas". This has caused operating expense and introduces inconveniences because of the relative scarcity of helium. Current experiments are leading to final and conclusive proof that nitrogen, a universally available gas, is both satisfactory and desirable as a cover gas. In fact, it is known that the SEA WOLF operated with nitrogen as a cover gas during its entire operating period; development work now undertaken is primarily aimed at investigating the effects of nitrogen on those reactor and system areas which differ significantly from those of the SEA WOLF. In any event, future sodium-cooled systems will be designed to operate with cover gases other than helium, based on the knowledge both presently available and becoming immediately available through current development efforts.

Maintenance of sodium systems, once considered a highly delicate and specialized operation, has become a routine matter for those accustomed to dealing with these problems. No special skills or precautions are involved, other than a few routine measures designed to minimize (but not necessarily eliminate) contact between sodium and oxygen. For instance, maintenance 


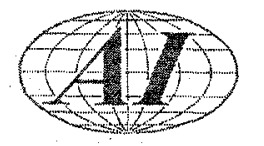

operations on the SRE piping systems are commonly performed with this piping full of frozen sodium; nitrogen purging of the area to be maintained or altered is easily performed, and many system repairs and alterations have been made in this fashion. This experience is not unique to the SRE; it is common to all the laboratories currently dealing with liquid metals.

The induced radioactivity of $\mathrm{Na}^{24}$ constitutes a problem which creates the necessity for some special handling conditions. With the back log of SIR, EBR I, and SRE experience, reactor systems have been devised which eliminate many of the problems associated with this radioactivity. No insoluble difficulties have yet been uncovered, nor are they expected. In any event, the 15 -hour half-life of $\mathrm{Na}^{24}$ permits access to sodium systems in about 10 days, even if no special precautions are taken.

\section{H. CURRENT AND PREDICTED CAPITAL COSTS}

Capital investment in a nuclear power plant is not established by paper studies in which the designer is not necessarily committed to produce at the predicted cost; it is established by the obtaining of fixed prices for reactor system components, and the construction of the reactor itself. Once these costs have been firmly established, reasonable extrapolations of cost reductions, resulting from technological advances, may be made. Two land marks in the SGR system are available: the SRE which has already been constructed, and the HNPF under construction.

The installed cost of the SRE, which was specifically designed as a flexible reactor experiment and originally had no steam-turbine equipment associated with it, is approximately $\$ 1200 / \mathrm{kwe}$. Sufficient operating experience has been accumulated to warrant an examination of the necessity for many of the systems and components originally incorporated in the reactor for experimental purposes and to protect against uncertainties in design. Operating data have been gathered which establish the potentialities of this system for generating power in its present size; unfortunately, many of these potentialities cannot be realized because of limitations such as undersized core-tank nozzles, unpierced moderator cans, etc., which are no longer accessible for alteration. These studies indicate that, by elimination of nonessential equipment such as air-blast heat exchangers, 


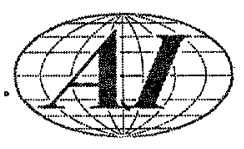

extra instrumentation, standby systems, etc., and by increasing the power level of the reactor by additional loading and increased flow rates which have been experimentally demonstrated to be possible, the installation cost of even this relatively small size reactor could be reduced to about $\$ 500 / \mathrm{kw}$ including turbine. There are, of course, uncertainties in this analysis, but the figures are borne out to a degree by the established costs of the Hallam plant which appear to be about $\$ 480 / \mathrm{kw}$. Needless to say, the design improvements made possible by development efforts since the inception of these particular reactor designs result in significant capital cost decreases. The high power capabilities of this reactor, coupled with a relatively small increase in size as power increases, (inherent in the graphite-moderated design), bring installed costs to the neighborhood of $\$ 200 / \mathrm{kwe}$ in sizes greater than $200 \mathrm{Mwe}$. A detailed study substantiating these conclusions is in preparation and will be published in early May.

Again, outstanding characteristics of this type of reactor are the lack of inherent limitation on size and power, and the low pressure and high temperature which permits electric power to be generated in the largest turbo generator unit sizes now being manufactured as "preferred" units in the United States. 


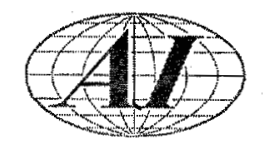

\section{SUMMARY}

The foregoing brief description of the state of sodium technology, and in particular sodium-graphite-reactor technology, is subject to expansion, documentation, and verification should the requirement arise. It is significant to note that, despite the relatively low level of support when compared to other reactor systems, technology has progressed to the point where exploitation of the unique capabilities of liquid metals is now possible. Technically, information is available to make power costs competitive in every way with those of other systems immediately. By demonstration programs involving applications of this technology, rather than development of whole new fields of technology, power costs competitive with fossil fuels appear entirely feasible within 7 to 10 years. Only through the construction of experimental and demonstration plants, however, will this be possible. The technology of liquid metals is well known and familiar to only a few; the simplicity inherent in well-executed sodium-cooled-reactor designs must be demonstrated before general acceptance by organizations unfamiliar with sodium technology (except perhaps as a memory of college chemistry laboratories) can be assured. 


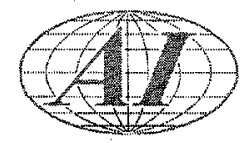

\section{SODIUM REACTOR PROGRAM FOR ECONOMIC POWER}

The background of sodium technology as it exists in 1959 has been explained previously; the SRE is operating now as a source of engineering information, a high temperature fuel element irradiation facility, and a source of hot nonradioactive sodium for component test. Steam generator configurations of novel design are being tested now; development purification devices, sodium instruments, and materials studies are part of a continuing research program. The outlet temperature of the SRE will be raised to $1000^{\circ} \mathrm{F}$ in fiscal 1960 , subject to successful completion of a series of material tests on zirconium. These tests are designed to demonstrate that no significant damage will be done to the reactor by operating at these temperatures. A thorium - uranium fuel load will also be inserted in the SRE to acquire information on the long-term irradiation stability of this fuel. A developmental control system, based on experimental information now at hand, will be installed to demonstrate the load-following capabilities of this plant. Though the SRE is not designed in any way as an engineering prototype reactor, cost studies based on experimental information and reasonable extrapolation of this information will continue, so that these results may be applied to future SGR plants. Operation of this reactor with other experimental fuels, though not necessarily complete loadings, is planned as a continuing program until at least 1967. The flexibility of this experimental reactor permits rapid changing of fuel and quick evaluation of irradiated fuels in the adjacent North American Aviation hot cell. It is planned that the experimental functions of this plant will be gradually reduced over its operating life, as new reactors become available, and that within about 3 years the operating staff will be reduced to that necessary to operate and maintain the reactor.

Commencing in 1962, the HNPF will become available for extensive fuel irradiation and as a source of engineering information on large-scale sodium systems. The initial loading of this plant will be a U-10\% Mo alloy fuel. Completion of development efforts on uranium monocarbide fuel, now underway, will culminate in the loading of a long-lived fuel, probably in 1964. Starting at $925^{\circ} \mathrm{F}$ outlet temperature, power conditions will be raised gradually to a $1000^{\circ} \mathrm{F}$ outlet temperature, permitting the reactor and system to operate at 96-Mw-net electrical power. At this time, power costs are estimated to be about $12 \mathrm{mills} / \mathrm{kw}-\mathrm{hr}$, 


\section{(11)}

of which approximately 3 mills are accounted for in fuel cycle costs. The Hallam plant retains many of the design concepts embodied in the SRE, and represents the most advanced design in which confidence could be placed in 1956, the year of inception of design. Parallel development programs, along with increasing sophistication in liquid-metal technology, have indicated that the objectives of improved neutron economy, decreased capital costs, higher sodium temperatures (permitting generation of higher temperature steam), system simplicity, and high specific power may be met with an advanced concept. Conceptual design of this advanced concept has been completed; it appears quite reasonable to test the concept in a 10-Mwt experimental reactor.

This advancedconcept ${ }^{*}$ consists of a graphite moderated and reflected core contained within a single enclosure as differentiated from the SRE in which the graphite is "canned" in 119 individual packages. This enclosure, referred to as the "calandria", is made of stainless steel and thus is not subject to the temperature limitations imposed on zirconium and currently available zirconium alloys. Primary sodium coolant flow is up through process tubes piercing the calandria vertically. Fuel elements are suspended within these process tubes and supported from the top shield. Hot outlet sodium from the process tubes forms a pool above the calandria tank and "overflows" over a barrier downward into heat exchangers contained wholly within the reactor vessel. Heat is transferred to secondary sodium coolant, which is circulated to the external steam generating system. Activation of secondary coolant is prevented by a neutron shield, which forms the barrier over which the heated primary sodium overflows. Below the heat exchangers, which are located in the annulus formed by the neutron shield and the core vessel, are electromagnetic pumps. These pumps furnish the necessary heat to circulate primary sodium coolant through the calandria and heat exchangers. Thus all components and all radioactive primary sodium are contained within the main reactor vessel. Primary electromagnetic pumps operate through the (nonmagnetic) wall of the core vessel and are removable for immediate maintenance as they have not been activated by neutrons, or exposed directly to liquid metal. The advantages of this concept are:

a) Higher neutron economy through elimination of sodium coolant in high-thermal-flux region of the core (as in SRE design)

*Identified as SCRE-O in later tables 


\section{(11i)}

b) Increased reliability through containment of radioactive sodium within a single-core vessel

c) Cost savings resulting from elimination of primary piping and heatexchanger galleries

d) Reduced maintenance costs of pumps, due to ability for immediate repair (no waiting for sodium activity to decay)

e) Higher power density in core through flux flattening by nonuniform fuel distribution. (economically unfeasible in canned-moderatortype core)

f) High outlet sodium temperatures due to use of stainless steel in high temperature regions

g) Maximum flexibility of reactor and system components to accommodate the thermal shocks possible in sodium-cooled-reactor systems.

Research and Development efforts, now in progress, are necessary to prove out the novel features of this design. These are considered to be:

a) Proof tests of bellows which take up differential expansion between calandria shell and process tubes

b) Effectiveness of neutron shielding

c) EM pump development.

A prototype electromagnetic pump is now operating; bellows are on test; and a prototype section of shielding is being experimentally examined in a test reactor setup. Construction of a 10-Mwt-reactor experiment could begin in December of 1959; conceptual design is substantially complete and detailed design could begin on July 1, 1959. This reactor could be completed by December 1961 as far as the technical aspects of construction are concerned. Dissipation of heat generated by this plant would be in the SRE air-blast heat exchanger. The cost of this experiment is estimated at about $\$ 4.25$ million. Sufficient capabilities in heat-transfer surface will be included to determine experimentally the ultimate potential of this reactor; heat fluxes of at least 1 million Btu/hr/ft ${ }^{2}$ in experimental fuel elements are expected. 



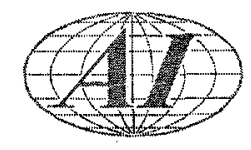

reactor system concept is a further extension of the overflow calandria concept (SCRE-O). The major difference lies in the method of heat transfer to the steam and the almost complete elimination of facilities for a secondary nonradioactive coolant system. The vessel containing the primary sodium system would be used as the sodium-to-sodium heat-transfer surface and the steam generator will be located concentrically around the reactor tank, submerged in secondary sodium. Thus, the intermediate heat exchanger is eliminated as such. Extended core vessel surface area will be required. Primary sodium coolant will be circulated by electromagnetic pumps as in the previous concept. The steam generators themselves will be necessarily of a "once-through" configuration; the technology of the once-through sodium-heated steam generator will have been well established by that time by the currently installed SRE steam generator and the Enrico Fermi fast-breeder steam generator which are both of a "once-through" construction. The advantages of this concept parallel those of the "overflow" design with the additional advantage of extreme compactness of reactor and heat-transfer systems. The proposed steam generators are of the simplest configuration possible with liquid metal, and further substantial capital costs are expected to result, chiefly from reduction of steam-generator cost. *

Development problems in this proposed scheme are expected to be concerned chiefly with the heat-transfer capabilities of the core vessel. Circulation of the sodium in which the steam generators are immersed will be necessary and will be accomplished by electromagnetic pumps in all probability. In event of a steam-generator tube rupture, direct introduction of sodium - water reaction products into the core will be prevented by the core vessel wall; rupture discs on the vessel containing the steam generator tubing will carry away and provide a safe disposition of both overpressure and reaction products. Currently available information from APDA tests indicates that such a scheme is feasible; sufficient information from these tests is available to design adequate and safe protection measures. Successful operation of a 10-Mwe experiment (SCRE-B) will achieve what reactor designers have long been seeking, the generation of $1050^{\circ} \mathrm{F}$ steam at $2200 \mathrm{psi}$ in the immediate vicinity of the reactor core itself.

*This concept is identified 28 SCRE-B in subsequent tables. 


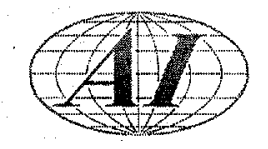

Construction cost of this experiment is estimated at $\$ 6$ million, including the steam-generating and turbine equipment which must be associated with this particular configuration.

The 250-Mwe-reactor prototype will demonstrate the effectiveness of reactor scaleup; successful operation of the advanced design experiment noted above will demonstrate the practicability of steam generation in the manner described. Thus, with these two additonal landmarks, a reasonable choice leading to establishment of the reactor design most likely to produce power at $6 \mathrm{mills} / \mathrm{kw}-\mathrm{hr}$ or less may be confidently made.

By this program, two experimental reactors and one large prototype in addition to the current efforts on HNPF and SRE will enable sodium-graphitereactor technology to come of age. It is confidently expected that installation costs of a 300-Mwe reactor, based on the most successful design resulting from this program, will have an installed cost of less than $\$ 200 /$ Kwe at 1959 prices. As previously noted, these figures will be substantiated upon completion of the 250-Mwe study now in progress. Improvements in fuel cycle economy are certainly to be expected; in the event that these are brought close to $2 \mathrm{mills} / \mathrm{kw}-\mathrm{hr}$, 6-mill power will be at hand in 1966.

A parallel program which is being presently exploited in sodium-cooled reactors is that of breeding. Sodium coolant for breeder reactors in the fast and epithermal range of neutron energy is almost mandatory; the power density necessary in these reactors is simply not compatible with coolants of lesser heattransfer properties. Commencing with EBR I in 1952, and passing through the Enrico Fermi fast breeder demonstration, EBR II with its integrated fuel processing facility is now under construction. The latter two reactors will provide the required milestones for accurate cost estimation of central station plants. Simultaneously, the uranium - thorium cycle is being intensively investigated by a group of private electric utility companies. This latter study is designed to eventually produce an epithermal thorium breeder reactor of 400-Mw capacity in 1967. Studies are also being conducted on a "coupled thermal-fast" breeder reactor. It is expected that the combination of experience gained by EBR II, Fermi, and the advanced epithermal thorium reactor will demonstrate the capability of these systems to produce $6-$ mill power by 1968 . At this time, 


\section{(11)}

selection of the optimum breeding cycle can be made, dependent on the needs of the nation's economy and the requirements and supply of fertile materials in both this country and abroad.

The advanced epithermal thorium reactor is designed specifically for optimum power costs, and, if the physical constants as determined by the current research program are such as to permit economical power, this reactor will be built to demonstrate power costs of $6 \mathrm{mills}$ or less at 1959 prices. In any event, providing the neutron economy of the uranium - plutonium and thorium - uranium cycles permit, either or both cycles may be chosen as the national interest dictates. This choice can be made with the confidence engendered by a current research program and the construction of at least four demonstration reactors of this type: (EBR I, EBR II, Fermi, and AETR).

It should be noted that the advances in system technology demonstrated in the SGR development program will be applicable in large measure to the parallel but independent fast and epithermal programs; intensive cross-fertilization of sodium-systems technology will be maintained in the future as has been done to date, with corresponding benefits to both programs.

In summary, it appears entirely probable that economical nuclear power can be made through one and quite possibly two separate development routes, one breeding and one converting, by 1967, in liquid-metal-cooled reactor systems. The technology is either in hand or will soon be available if current development programs are vigorously continued as recommended. These recommendations are founded on a large amount of information developed from encouraging operating experience with the SRE and other sodium-cooled reactors. 


\section{(11)}

\section{APPENDIX - SODIUM COOLED REACTOR FUEL DEVELOPMENT}

The AI fuels development program for sodium-cooled reactors has actively investigated three fuel systems: (1) uranium metal, (2) uranium carbide, and (3) thorium - uranium. Fuel fabrication and reprocessing development is complete for uranium-metal fuel. Irradiation stability of unalloyed uranium is being evaluated in the first SRE core loading. A peak burnup in excess of $1500 \mathrm{Mwd} / \mathrm{t}$ is anticipated. Cast U-10 w/ Mo fuel is being developed for the first Hallam loading with expected peak burnup of at least $7000 \mathrm{Mwd} / \mathrm{t}$. Uranium-carbide fuel is currently under active development in the three areas of materials, fabrication, and reprocessing. The great potential of this fuel has been demonstrated in the achievement of $7000 \mathrm{Mwd} / \mathrm{t}$ at $1600^{\circ} \mathrm{F}$ central fuel temperature with negligible volume change. Uranium-carbide fuel is destined for the third SRE loading, the second Hallam loading, and all subsequent fuel for thermal reactors.

Present indications are that the initial fuel loading for AETR will be a Th-Pu alloy. Probable feasibility of this fuel is indicated by the excellent performance obtained on Th-U alloy fuel. MTR tests on Th-U fuel indicate a burnup potential in excess of $11,000 \mathrm{Mwd} / \mathrm{t}$ at a temperature of $1200^{\circ} \mathrm{F}$. Confirmation of small scale tests on this fuel will be obtained from the second SRE loading schedule for the near future. It is planned to irradiate at least a partial loading of Th-Pu fuel in SGRE commencing approximately July 1964 with results to be available prior to freezing the AETR initial loading.

The attached bar graph and discussions on the three fuel types summarize the completed, current, and proposed development program and schedule. Use of each fuel in core loadings of sodium reactors is also shown.

\section{A. URANIUM METAL FUEL}

Unalloyed uranium was selected as the first core loading for the SRE at a time when there was a complete lack of high-temperature irradiation data on uranium and its alloys. Based on present knowledge of metallic fuels at high temperatures, the use of unalloyed uranium in an SGR no longer appears practical. Uranium alloys of interest for SGR application include $\mathrm{U}-\mathrm{Mo}, \mathrm{U}-\mathrm{Zr}, \mathrm{U}-\mathrm{Pu}$, U-Nb-Zr, U-Mo-Al, and U-Mo-Si. Specimens of these materials are undergoing irradiation in SRE. This effort will continue through 1964. 
Use of U-10 w/o Mo as the fuel for HNPF Core I was predicted on the need for an interium fuel material which would perform satisfactorily under Hallam's design conditions for a period of 18 months, starting January 1962. Fuel element replacements, starting September 1963, would use UC fuel. The selection of U-10 w/o Mo was based on data available on various $U-M o$ alloys as of November 1958. Evaluation of the se data indicated that a core using U-10 w/o Mo would provide the requisite $7000-\mathrm{Mwd} / \mathrm{t}$ peak burnup.

\section{B. URANIUM CARBIDE}

Uranium carbide appears to be the ideal fuel for high-temperature sodiumcooled reactors. This fuel has reasonably high uranium content, high conductivity, compatibility with sodium, and no transformations or other temperature limitations up to its melting point of $4300^{\circ} \mathrm{F}$. Development of this fuel is considered a major breakthrough for sodium-cooled reactors since it provides the possibility of designing high power density, compact cores. Ir radiation tests on cast uranium carbide with fuel temperatures as high as $1800^{\circ} \mathrm{F}$ have shown only $2 \%$ volume increase at $7000 \mathrm{Mwd} / \mathrm{t}$. The current development program will irradiate samples to 17,000 and $24,000 \mathrm{Mwd} / \mathrm{t}$ in SRE and MTR respectively. Additional physical property and corrosion tests are under way. Completion of most of this work is scheduled for July 1960 with the longer irradiations extending to July 1962. Low decontamination reprocessing work shows encouraging preliminary results.

\section{THORIUM ALLOYS}

Development work has been carried out on several highly enriched thoriumuranium alloys. Irradiations in MTR at a temperature of $1200^{\circ} \mathrm{F}$ have shown good dimensional stability up to $11,000 \mathrm{Mwd} / \mathrm{t}$. SRE tests, now in progress, show good stability at 1000-Mwd/t burnup. A full core loading has been fabricated and is ready for insertion in the SRE for a projected average burnup of $6000 \mathrm{Mwd} / \mathrm{t}$.

Encouraging results have been obtained in development of a low decontamination process for separating uranium from thorium based on their differential solubility in molten magnesium. This reprocessing method gives promise of a low-cost fuel cycle. 


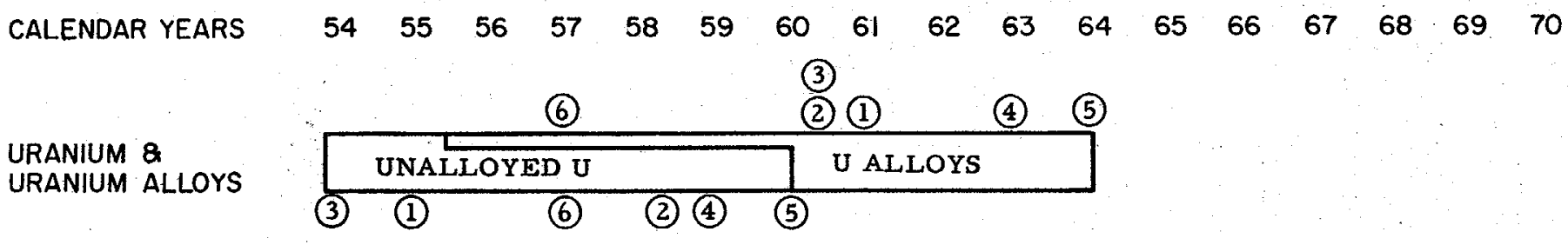




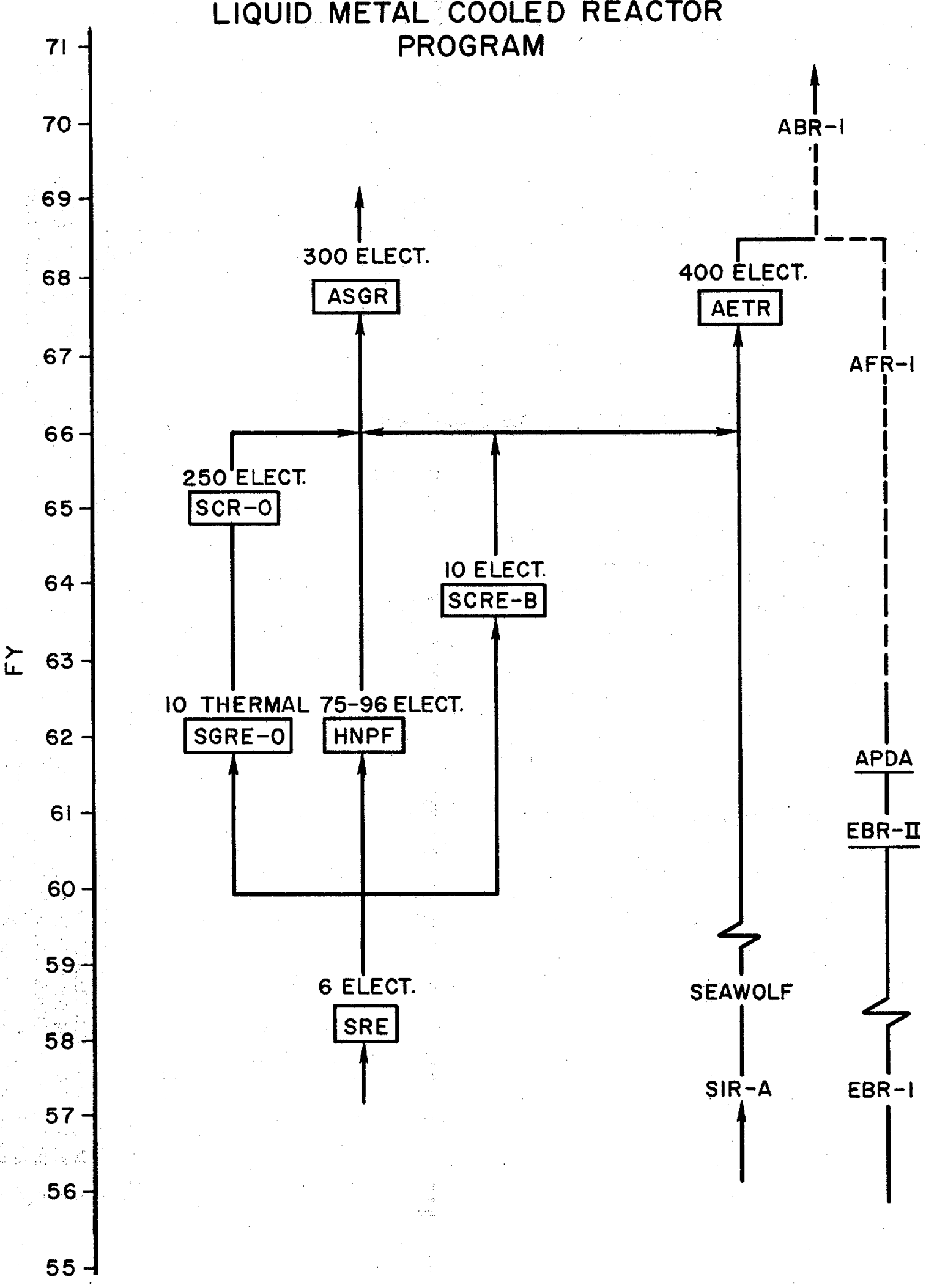

LIQUID METAL COOLED REACTOR
PROGRAM 
SODIUM-COOLED REACTOR PROGRAM

FISCAL YEAR

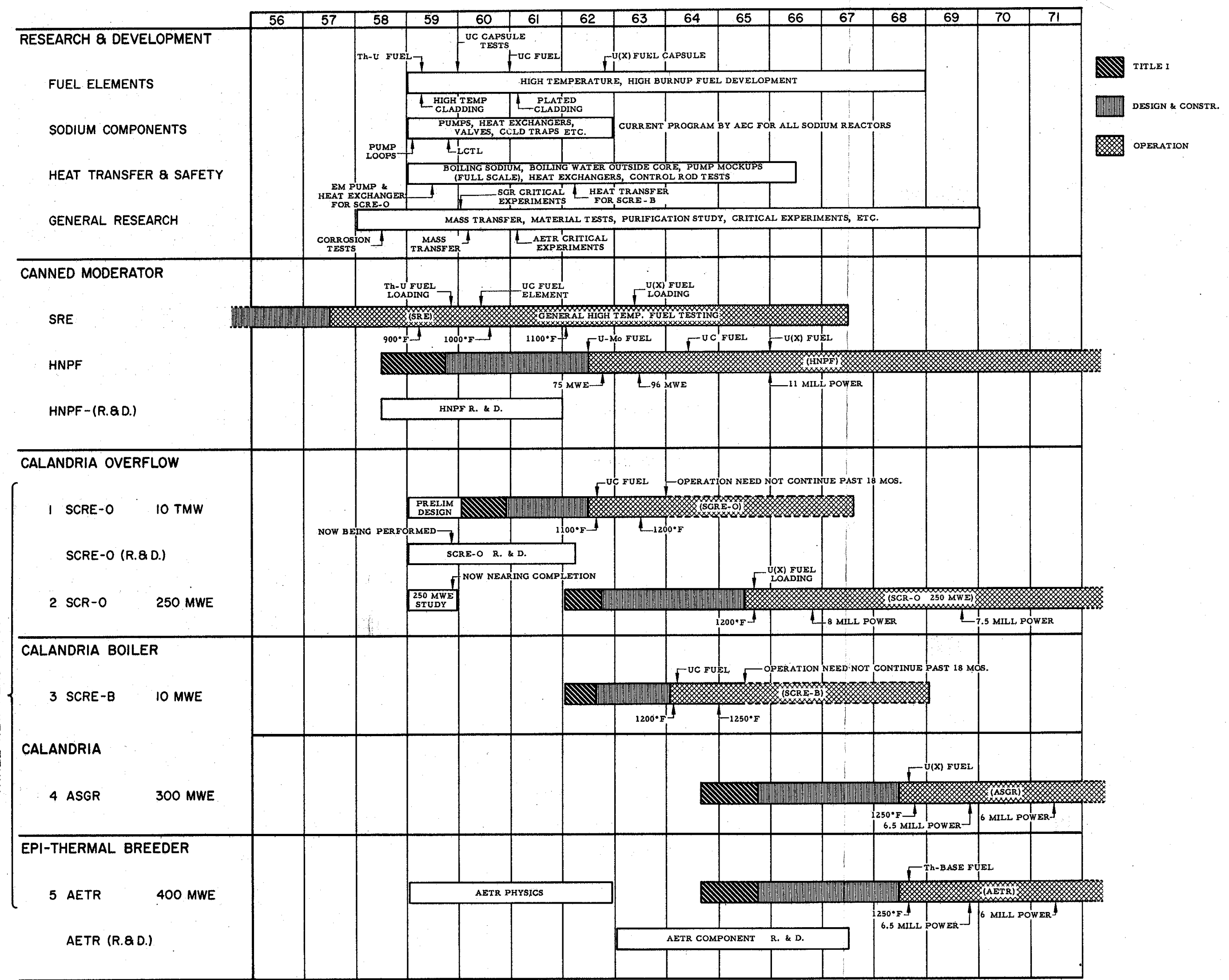

Note: Power costa shown une scalated (1959) dollars. 


\section{Summary Costs}

Total Program Cost

Total Cost to AEC

Total Cost to Utilities

Total Program Cost

Total Cost to AEC

Total Cost to Utilities
$\$ 216,000,000$ $106,000,000$ $110,000,000$

$\$ 179,000,000$

$96,000,000$

$82,000,000$
For 550 installed EMW plus

10 Mwe on SCRE-B

(includes escalation)

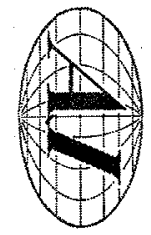

